\title{
NMR-Based Metabolomics: A Probe to Utilize Biodiversity
}

\section{Lúcia P. Santos Pimenta, Hye Kyong Kim, Robert Verpoorte, and Young Hae Choi}

\begin{abstract}
Metabolomics is a comprehensive profiling tool used to identify qualitatively and quantitatively all the metabolites present in a biological system. As the number of metabolites in a living being is assumed to be around 30,000 , it is necessary to use an adequate extraction procedure and a good analytical technique to perform metabolomic analyses. Each analytical platform used in metabolomics has both advantages and disadvantages in terms of the sensitivity and resolution for metabolites to be detected. Of the methods, nuclear magnetic resonance (NMR) spectroscopy has been proved to have several advantages over other MS-based methods. NMR provides an efficient, robust, and nondestructive metabolomics analysis of crude extracts or samples as well as easy quantitation without calibration curves for each metabolite, although it shows relatively low sensitivity than MS-based methods. Thus, NMR-based metabolomics have been often used for the first step to capture the insight of the metabolome of organisms. This chapter presents general steps of NMR-based metabolomic analysis involved in the study of biodiversity.
\end{abstract}

Key words ${ }^{1} \mathrm{H}$ NMR-based metabolomics, Sample preparation, Multivariate data analysis, Twodimensional nuclear magnetic resonance (2D-NMR) spectroscopy

\section{Introduction}

Metabolomics is the qualitative and quantitative measurement of all metabolites of an organism. It is a powerful tool used to understand more comprehensively the highly regulated and complex biochemical networks in the most fundamental cell by measuring the metabolome. Considered the most recent "omics" technologies, the metabolome is postulated to be more closely related to the phenotype of an organism, being more sensitive than the proteome and the transcriptome to external factors that contribute to phenotypic differences between specimens [1]. The metabolome provides end products of gene expression and can define the biochemical phenotype of a cell or tissue. Metabolomics is the characterization of the metabolome and can be used to monitor and assess gene 
function, yielding more information and being more versatile than the other "omics" about functional genomics.

Although metabolomics can give a holistic approach to an organism the metabolic changes involved in response to a biotic or abiotic perturbation, is very difficult to completely achieve. Considering that the total number of metabolites within the plant kingdom, including primary and secondary metabolisms, is estimated to be over 200,000 in total and 30,000 in a single organism, they are present in different ranges of concentration in each organism and there is no single satisfactory metabolomics platform to fulfill the requirements to detect all metabolites. Reproducibility is the most important requirement to achieve in order to develop a metabolomics protocol. The other criterion is the ease of quantification and identification of the metabolites. Among the major problems to fulfill these requirements is how to extract all the metabolites inside a sample, which is practically impossible. Once the sample is treated, for example, by extraction, only the soluble compounds are obtained and insoluble part is not detected [2]. When separation is performed, certain compounds are lost: as such, information will be always lost. Furthermore, all metabolites should be analyzed using an optimized method that can detect all the metabolites extracted at the same time in one single experiment is another difficult task.

Each one of the analytical methods used in metabolomics has its own advantages and limitations, which are related to the differences in polarity, chemical property, stability, and concentration of the high number of metabolites [3]. Gas chromatography (GC) is sensitive but requires volatility of compounds; liquid chromatography (LC) can detect compounds in a certain polarity range. Both MS-based methods have problems of reproducibility, among others on the long-term, as they depend on commercial columns which tend to change through time. Even more importantly, each compound has a different detector response in GC-MS and LC-MS, thus requiring calibration curves for each individual compound if absolute quantification is required. Mass spectrometry (MS) offers high resolution and in terms of sensitivity is the best method, but reproducibility (very much matrix-dependent) and different detector responses are a problem for quantification. Nevertheless, ${ }^{1} \mathrm{H}$ NMR is highly reproducible and easy for quantification as signal intensity is directly related to the molar concentration. However, it has low sensitivity and resolution compared to the MS-based methods [3]. In fact, none of the existing methods are able to achieve the identification and quantification of all metabolites in an organism.

As a significant number of compounds are present in an organism, the data collected will be vastly large. The enormous amount of data collected needs to be processed and treated to obtain biological interpretation. Chemometric tools have been used in data 
analysis and in most cases, multivariate data analysis, such as Principal Component Analysis (PCA) and Partial Least SquaresDiscriminant Analysis (PLS-DA), is employed routinely to extract information from large data sets [4]. A large number of observable variables after multivariate data analysis give the information required. Next step is to identify the metabolites responsible for the biological question and is critical in a metabolomics analysis. However, very few compounds can be identified by the major detection methods used in metabolomics such as NMR and MS [5]. More extensive works for the identification should be elaborated for the future direction of metabolomics. Once the signals are identified as compounds, correlations between metabolites and responses, grouping and all the experimental data can be used in any time, permitting to construct a hypothesis or explain the observations made [4]. The differences between the samples and the identified compounds connected with them will provide a holistic vision about the system. "A single identified metabolite has more meaning than scores of unidentified signals."

In this chapter, we focus mainly on NMR-based metabolomic analysis, including five general practical steps: sample harvesting, sample preparation (grounding, drying, extraction), data acquisition (analysis based on MS or NMR spectrometry), data processing including multivariate data analysis, and identification of metabolites $[6,7]$.

\section{Materials}

\subsection{Sample \\ Preparation \\ Components \\ (Harvesting and \\ Drying)}

\subsection{Extraction Components (See Note 2)}

The materials and reagents described here are required for an NMR-based metabolomics. Prepare all solutions with deuterated solvents.

1. Dewar barrels.

2. Liquid nitrogen ( see Note $\mathbf{1}$ ).

3. Freezer $\left(-80^{\circ} \mathrm{C}\right)$ for sample storage.

4. Mortar and pestle.

5. Plastic tubes.

6. Freeze-dryer for sample drying.

1. Phosphate buffer $(90 \mathrm{mM}, \mathrm{pH} 6.0): 1.232 \mathrm{~g} \mathrm{KH}_{2} \mathrm{PO}_{4}, 10 \mathrm{mg}$ TMSP- $d_{4}$ in $100 \mathrm{~mL} \mathrm{D} \mathrm{D}_{2} \mathrm{O}$ (see Note 3 ).

2. 1.0 M NaOD.

3. 3-(trimethylsilyl)propionic-2,2,3,3- $d_{4}$ acid sodium salt (TSP), 99 at.\% Deuterium oxide $\left(\mathrm{D}_{2} \mathrm{O}\right)>99.9$ at.\% D.

4. Methanol- $d_{4}\left(\mathrm{CD}_{3} \mathrm{OD}\right) 99.8 \%$.

5. Sodium deuteroxide ( $\mathrm{NaOD}) 99.5 \%\left(40 \%\right.$ in $\left.\mathrm{D}_{2} \mathrm{O}\right)$. 
2.3 Equipment

1. Ultrasonicator operating at a high frequency $(\geq 2 \mathrm{MHz})$.

2. Microcentrifuge.

3. $2 \mathrm{~mL}$ Eppendorf tubes.

4. $\mathrm{pH}$ meter with electrode.

5. $5 \mathrm{~mm}$ NMR tubes.

3 Methods

\subsection{Harvesting Plant Material}

\subsection{Sample}

Preparation

\subsection{Extraction}

3.3.1 Two-Phase

Extraction Method for NMR

Analysis (See Note 8)
3.3.2 Single Solvent Extraction Method for NMR Metabolomics (See Note 9)
1. Prepare container filled with liquid nitrogen.

2. Isolate desired part (leaf, root, flower, etc.) from plant and transfer to plastic bag.

3. Keep plastic bag in the liquid nitrogen ( see Note 4).

The next step after harvesting the plants is to prepare the plant material for the extraction procedures. The sample preparation steps include grounding, drying, and weighing.

1. Precool the pestle and mortar.

2. Place harvested plant material in the pestle and grind using mortar under liquid nitrogen.

3. Transfer powdered material to tubes ( see Note 5 ).

4. Place them in the freeze drier for 1-2 days (see Note 6).

5. Weight samples precisely and transfer to tubes for extraction ( see Note 7).

1. Add $4 \mathrm{~mL}$ of chloroform, $4 \mathrm{~mL}$ of methanol:water (1:1) to $100 \mathrm{mg}$ of dried plant material.

2. Vortex them for $30 \mathrm{~s}$.

3. Ultrasonicate for $5 \mathrm{~min}$ and centrifuge at $14,000-17,000 \times \mathrm{g}$ for $20 \mathrm{~min}$ at $4{ }^{\circ} \mathrm{C}$.

4. Take upper phase of methanol/water fraction (polar metabolites) and lower phase of chloroform/methanol fraction (nonpolar metabolites).

5. Evaporate both fraction using rotary evaporator and add $1 \mathrm{~mL}$ of chloroform- $d$ to chloroform-methanol fraction and $1 \mathrm{~mL}$ of methanol- $d_{4}$ and $\mathrm{D}_{2} \mathrm{O}\left(\mathrm{KH}_{2} \mathrm{PO}_{4}\right.$ buffer, $\mathrm{pH}$ 6.0) to methanolwater fraction for NMR measurement.

1. Add $0.75 \mathrm{~mL}$ of methanol- $d_{4}$ and $0.75 \mathrm{~mL}$ of $\mathrm{KH}_{2} \mathrm{PO}_{4}$ buffer $(\mathrm{pH} 6.0)$ in $\mathrm{D}_{2} \mathrm{O}$ containing $0.01 \%$ trimethylsilylpropionic acid sodium salt (TMSP, w/w) solution to 50-100 mg of plant materials.

2. Vortex for $1 \mathrm{~min}$ at room temperature. 
3. Ultrasonication for $10-20 \mathrm{~min}$ at room temperature.

4. Centrifuge at $14,000-17,000 \times g$ for $15 \mathrm{~min}$ at room temperature until obtain a clear supernatant.

5. Transfer $800 \mu \mathrm{L}$ supernatant to NMR tube (see Note 10).

3.4 Data Acquisition Using NMR

Spectrometry

(See Note 11)
1. Load NMR tubes inside the magnet of the NMR spectrometer.

2. Set the sample temperature to $298 \mathrm{~K}\left(25^{\circ} \mathrm{C}\right)$ and leave for a few minutes for thermal equilibration.

3. Tune and match the NMR tube.

4. Lock the spectrometer frequency to the deuterium resonance arising from the NMR solvents.

5. Shim the sample using either manual or automated method.

6. Start acquisition with 64 or 128 scan numbers, which takes 5-10 min.

\subsection{Data Processing and Multivariate Analysis}

1. Make a Fourier transformation of FID with $\mathrm{LB}=0.3 \mathrm{~Hz}$.

2. Manually phase the spectra and correct the baseline.

3. Calibrate the spectra using solvent signal or internal standard (see Note 12) (Fig. 1).

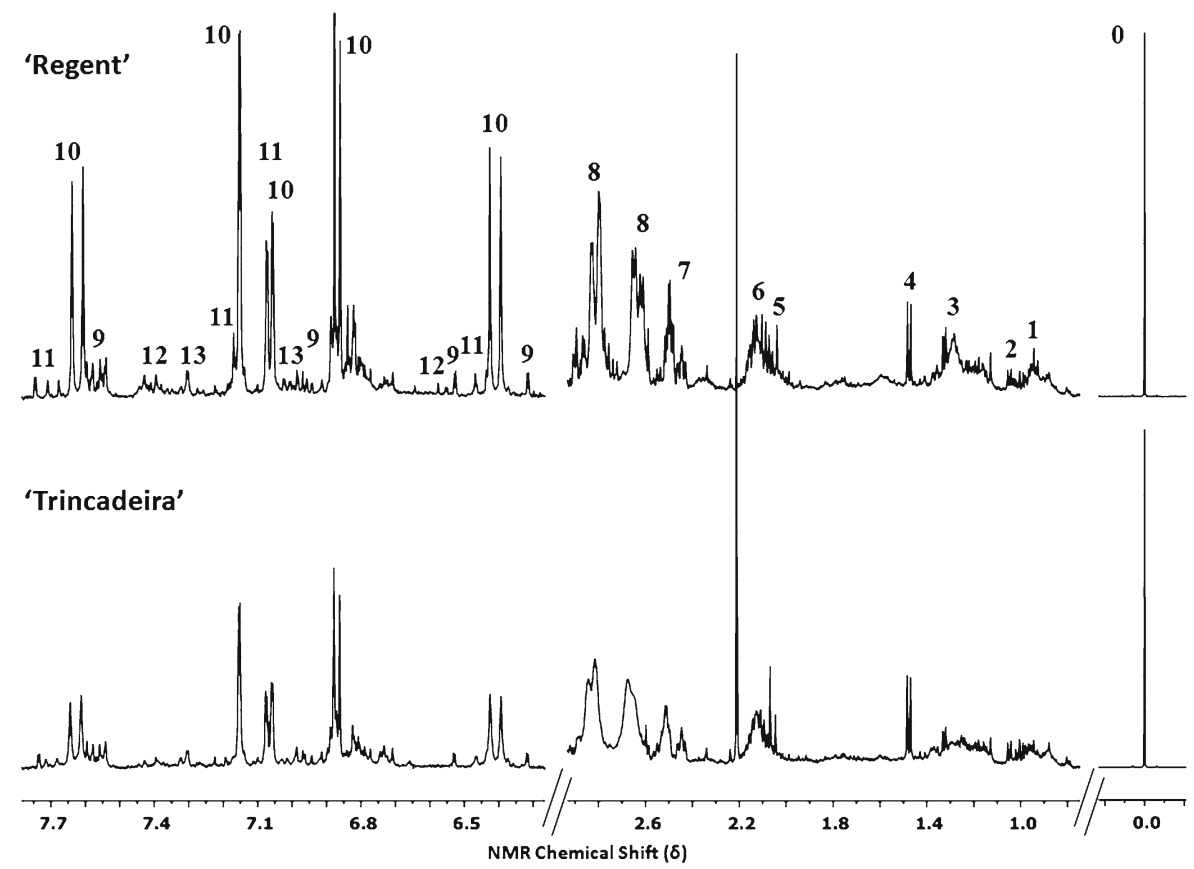

Fig. 1 Example of ${ }^{1} \mathrm{H}$ NMR spectra. Two different grape cultivars "Trincadeira" and "Regent" were analyzed after $48 \mathrm{~h}$ of pathogen inoculation. Numbers indicate major signals. 0: TMSP (internal standard), 1: leucine, 2: valine, 3: threonine, 4: alanine, 5: glutamate, 6 : proline and methionine, 7: glutamine, 8: malate, 9:quercetin glucoside, 10: caffeoyl moiety, 11: feruloyl moiety, 12: myricetin, 13: Tyrosine (adapted from ref. [14] after permission) 


\subsection{Identification of Metabolites}

\subsection{Applications of Metabolomics in the Plant Biodiversity}

\subsection{Chemotaxonomy and Classification of Plants}

\subsection{Plant Physiology or Ecology}

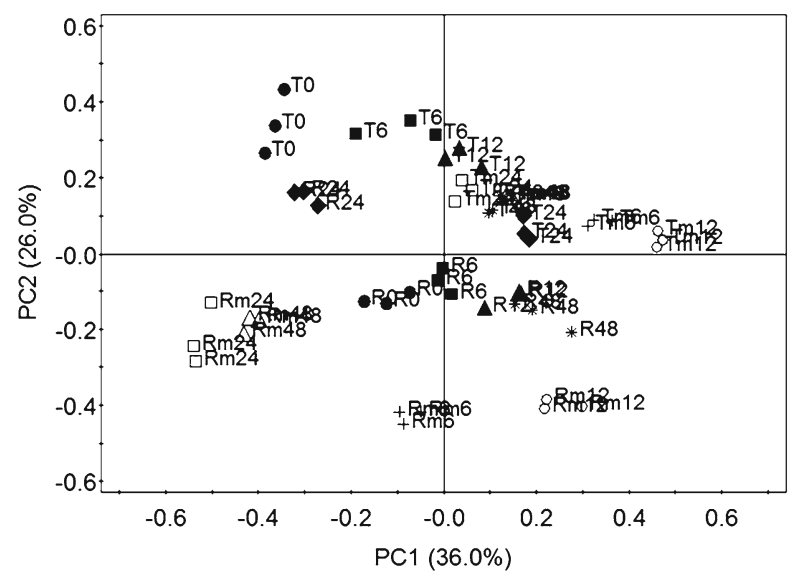

Fig. 2 Typical PCA score plot of two grape cultivars "Trincadeira" and "Regent." $\mathrm{T}$ and $\mathrm{R}$ represent each cultivar and number indicates time after inoculation with Plasmoparaviticola sporangia (adapted from ref. [14] after permission)

4. Convert NMR spectra to a suitable form for further multivariate analysis (see Note 13).

5. Perform multivariate analysis (PCA and PLS-DA) using SIMCA-P software or equivalent softwares (see Note 14) (Fig. 2).

1. Interpret the loading plots in case of PCA or PLS-DA to find the discriminating metabolites in the given samples.

2. Perform column chromatography if necessary to identify minor metabolites from the samples.

3. Analyze them using 2D NMR spectroscopy such as ${ }^{1} \mathrm{H}$ $J$-resolved spectroscopy, ${ }^{1} \mathrm{H}-{ }^{1} \mathrm{H}$ COSY (COrrelation SpectroscopY) or HMBC (Heteronuclear Multiple Bond Correlation).

NMR-based metabolomics has been successfully applied in many different fields such as chemotaxonomy, classification and quality control of (medicinal) plants as well as in the study of plant physiology and ecology. Using the protocols mentioned above, we have performed various studies and it has been well documented in several reviews $[3,5-8]$. Some of the examples are as below.

Chemotaxonomy study or classification can be an important issue to differentiate plants species or to identify adulterants. Using NMR-based metabolomics, it was able to differentiate 11 species of Ilex which has been used throughout South America [9, 10].

Plants responded chemically when they are under stress or infected with other organisms. It was well demonstrated in the study of Arabidopsis, Brassica, Senecio, and Grape [11-14]. 
Interaction with other organisms, Senecio with thrips (Frankliniella occidentalis) for instance, showed that changes in metabolism play an important role in the resistance of plants [13].

3.10 Quality Control of Medicinal Plants
Most of current quality controls are limited to detect one or two major active metabolites. Many medicinal plants, however, are used as crude extracts or plant powders, which means examine their metabolome is important to guarantee their pharmacological efficacy and safety. NMR-based metabolomics has been applied for the quality control of medicinal plants including Cannabis, Ephedra, Strychnos, and Ginseng [15-18].

1. Liquid nitrogen should be handled carefully and gloves and glasses should be used for protection. Dry ice can also be used to keep the sample material frozen during the harvesting.

2. There are different methods of extraction and the method to be chosen should be designed to detect as many metabolites as possible and meet the specific requirements of the analytical method to be used.

3. Adjustment of $\mathrm{pH}$ can be done after the stirring of the solution until total dissolution. Use 1.0 M NaOD.

4. To prevent the formation of new metabolites, as well as enzymatic and oxidative reactions the collection should be conducted very delicately and rapidly, and placing it in a liquid nitrogen tank or dry ice should immediately freeze the plant material. Harvested samples can be kept in a freezer $\left(-80^{\circ} \mathrm{C}\right)$ for weeks or months before extraction.

5. These samples can be kept in a freezer $\left(-80^{\circ} \mathrm{C}\right)$ for weeks or months before extraction.

6. In freeze-drying, frozen water in the sample sublimes under low pressure, passing directly from solid to gas phase. It is a rapid and mild method compared with other methods that use heat to evaporate and eliminate the water [19]. After drying, the samples these should be kept in a cold dark room to avoiding further enzymatic reactions.

7. The desirable amounts for NMR analysis is around 100$500 \mathrm{mg}$ of fresh material, or 50-100 mg of freeze-dried, however less can be used depending on the sample types.

8 . The extraction procedure should be repeated at least twice, to increase the yield extraction. Although this method of extraction allows to extract a broad range of polarities of compounds in both polar and nonpolar solvent, it is laborious, difficult to handle many samples, and some compounds can be lost during 
the procedure due to degradation or loss occurring in the long preparation time.

(a) For the metabolomics analysis by NMR the buffered mixture methanol:water $1: 1$ coupled to sonication has been extensively used $[6,11-13]$ and has shown to extract a broad range of primary and secondary metabolites. By using these solvents in deuterated form, extracts can be measured directly after extraction. To avoid shifts due to differences in $\mathrm{pH}$ a buffered solvent $\left(\mathrm{KH}_{2} \mathrm{PO}_{4}\right)$ should be used ( $\mathrm{pH}$ 6.0).

9. Extract can be kept for few days in the cold dark room $\left(0-4{ }^{\circ} \mathrm{C}\right)$ before NMR analysis. However, it is recommended to place at room temperature at least half an hour before NMR measurement to avoid poor shimming owing to the temperature difference of the samples.

10. All these steps are set up in the automation system, but it is recommended to do the first sample manually in order to obtain good resolved spectra.

11. We usually calibrate NMR spectra using TSP signal as $\delta 0.00$. TSP is a reference for calibration of NMR shift and can also serve as a reference (internal standard) in the quantification of metabolites.

12. At this stage, signals of remaining solvents have to be removed for the statistical analysis. AMIX software (Bruker Biospin $\mathrm{GmbH}$ ) is commonly used for converting spectra to an ASCII file. In this step, the peak is integrated into a small bin (bucket) the size of which is defined by the user. The size is preferably $0.04 \mathrm{ppm}$ in order to avoid the effect of signal fluctuation due to $\mathrm{pH}$ or concentration. The other softwares available are MestReNova (v 7.02. program 2011 Mestrelab Research S.L), a MATLAB tool box (ProMetab for Bruker format), NMR suite (Chenomx) for Bruker, JEOL, or Varian format, and ACD NMR Manager (Advanced Chemistry Development, Toronto, Ontario, Canada).

13. Several commercial software programs for multivariate analysis are available such as AMIX-TOOLS (Bruker Biospin GmbH), Matlab with statistics toolbox (MathWorks, Natick, MA, USA), Minitab (Minitab, State College, PA, USA), Pirouette (Infometrix, Bothell, WA, USA), SIMCA-P (Umetrics, Umeå, Sweden), SPSS (SPSS, Chicago, IL, USA), or Unscrambler (CAMO software, Woodbridge, NJ, USA).

14. As the first step of identifying metabolites, several database can be used such as NMR chemical shift database for natural products (http://nmrshiftdb.pharmazie.uni-marburg/de/ nmrshiftdb/), for pulse sequences of 2D-NMR and illustration of their mechanism (http://www.chem.queensu.ca/ FACILITIES/NMR/nmr/webcourse/), for commercial ${ }^{1} \mathrm{H}$ 
NMR Database of metabolites (ca. 250 metabolites) Chenomx Profiler (NMR suite) (see http://www.chenomx.com). Some books such as comprehensive NMR pulse sequences (S. Berger, S. Braun. 2004. in 200 and More NMR Experiments. Wiley$\mathrm{VCH}$ ) are useful. Other databases that might be potentially useful for metabolite identification using NMR spectra include the NMRShiftDB (www.ebi.ac.uk/NMRshiftdb/), the Spectral Database for Organic Compounds (SDBS: www. riodb0l.ibase.aist.go.jp), and the BioMagResBank (www. bmrb.wisc.edu). The ${ }^{1} \mathrm{H}$ NMR data of common metabolites found in plant are listed in Table 1.

\section{Table 1}

Most common metabolites found in plants by nuclear magnetic resonance (NMR)

\begin{tabular}{|c|c|c|}
\hline Group & Metabolites & Selected characteristic signals in NMR \\
\hline \multirow[t]{10}{*}{ Amino acid } & Alanine & $\delta 1.48(\mathrm{H}-3, d, J=7.2 \mathrm{~Hz})$ \\
\hline & Asparagine & $\delta 2.8(m), \delta 2.97(m)$ \\
\hline & Glutamate & $\delta 2.07(\mathrm{H}-2, m), \delta 2.36(\mathrm{H}-3, m)$ \\
\hline & Glutamine & $\delta 2.12(\mathrm{H}-2, m), \delta 2.48(\mathrm{H}-3, m)$ \\
\hline & Leucine & $\delta 0.96(\mathrm{H}-5, d, J=8.0 \mathrm{~Hz})$ \\
\hline & Proline & $\delta 4.08(\mathrm{H}-2, d d, J=8.6,6.4 \mathrm{~Hz}), \delta 2.34(\mathrm{H}-3, m)$ \\
\hline & Threonine & $\delta 1.32(\mathrm{H}-4, d, J=6.6 \mathrm{~Hz})$ \\
\hline & Tryptophan & $\begin{array}{c}\delta 7.20\left(\mathrm{H}-5^{\prime}, t, J=7.4 \mathrm{~Hz}\right), \delta 7.29\left(\mathrm{H}-6^{\prime}, t,\right. \\
J=7.5 \mathrm{~Hz}), \delta 7.32\left(\mathrm{H}-2^{\prime}, s\right) \delta 7.54\left({\mathrm{H}-7^{\prime}}^{\prime}, d,\right. \\
J=8.1 \mathrm{~Hz}), \delta 7.73\left(\mathrm{H}-4^{\prime}, d, J=7.9 \mathrm{~Hz}\right)\end{array}$ \\
\hline & Tyrosine & $\begin{array}{l}\delta 7.19(\mathrm{H}-2, \mathrm{H}-6, t, J=8.5 \mathrm{~Hz}), \delta 6.68(\mathrm{H}-3, \mathrm{H}-5, t \\
\quad J=7.5 \mathrm{~Hz})\end{array}$ \\
\hline & Valine & $\delta 1.00(\mathrm{H}-4, d, J=7.8 \mathrm{~Hz}), \delta 1.06(\mathrm{H}-5, d, J=7.8 \mathrm{~Hz})$ \\
\hline \multirow[t]{7}{*}{ Carbohydrates } & $\alpha$-Glucose & $\delta 5.18(\mathrm{H}-1, d, J=3.8 \mathrm{~Hz})$ \\
\hline & $\beta$-Glicose & $\delta 4.58(\mathrm{H}-1, d, J=7.8 \mathrm{~Hz})$ \\
\hline & Fructose & $\delta 4.17(\mathrm{H}-1, d, J=9.0 \mathrm{~Hz})$ \\
\hline & Sucrose & $\delta 5.40(\mathrm{H}-1, d, J=3.8 \mathrm{~Hz}), \delta 4.17\left(\mathrm{H}^{-} \mathrm{l}^{\prime}, d, J=8.5 \mathrm{~Hz}\right)$ \\
\hline & $\alpha$-Rhamnose & $\delta 5.10(\mathrm{H}-1, d, J=2 \mathrm{~Hz}), \delta 1.27(\mathrm{H}-6, d, J=6 \mathrm{~Hz})$ \\
\hline & $\beta$-Rhamnose & $\begin{array}{l}\delta 4.85\left(\mathrm{H}-\mathrm{l}^{\prime}, \text { br. } d, J<2 \mathrm{~Hz}\right), \delta 1.30(\mathrm{H}-6, d, \\
\quad J=5.5 \mathrm{~Hz})\end{array}$ \\
\hline & L-Fucose & $\delta 4.20(\mathrm{H}-1, d, J=7.9 \mathrm{~Hz})$ \\
\hline \multirow[t]{6}{*}{ Organic acid } & Citric acid & $\begin{array}{l}\delta 2.74(\mathrm{H}-2, d, J=17.6 \mathrm{~Hz}), \delta 2.56\left(\mathrm{H}-2^{\prime}, d,\right. \\
\quad J=17.6 \mathrm{~Hz})\end{array}$ \\
\hline & Formic acid & $\delta 8.46(\mathrm{~s})$ \\
\hline & Fumaric acid & $\delta 6.56(\mathrm{~s})$ \\
\hline & $\begin{array}{l}\gamma \text {-Amino-butyrate } \\
(\text { GABA })\end{array}$ & $\begin{array}{l}\delta 1.90(\mathrm{H}-3, m), \delta 2.30(\mathrm{H}-2, t, J=7.2 \mathrm{~Hz}), \delta 3.01 \\
\quad(\mathrm{H}-4, t, J=7.5 \mathrm{~Hz})\end{array}$ \\
\hline & Malic acid & $\begin{array}{c}\delta 4.34(\mathrm{H}-2, d d, J=6.6,4.7 \mathrm{~Hz}), \delta 2.74(\mathrm{H}-3, d d, \\
J=16.6,4.7 \mathrm{~Hz}), \delta 2.68(\mathrm{H}-2, d d, J=16.6,6.6 \mathrm{~Hz})\end{array}$ \\
\hline & Succinic acid & $\delta 2.56(s)$ \\
\hline
\end{tabular}




\section{Table 1}

(continued)

\begin{tabular}{|c|c|c|}
\hline Group & Metabolites & Selected characteristic signals in NMR \\
\hline \multirow[t]{13}{*}{$\begin{array}{l}\text { Phenylpropanoids/ } \\
\text { flavonoids }\end{array}$} & Kaempferol & $\begin{array}{c}\delta 8.04\left(\mathrm{H}-2^{\prime}, \mathrm{H}-6^{\prime}, d, J=8.6 \mathrm{~Hz}\right), \delta 6.74\left(\mathrm{H}^{\prime} 3^{\prime}, \mathrm{H}-5^{\prime},\right. \\
d, J=8.6 \mathrm{~Hz}), \delta 6.52(\mathrm{H}-8, d, J=2.0 \mathrm{~Hz}), \delta 6.28 \\
(\mathrm{H}-6, d, J=2.0 \mathrm{~Hz})\end{array}$ \\
\hline & $(+)$-Catechin & $\begin{array}{l}\delta 2.49(\mathrm{H}-4, d d, J=16.1 .8 .2 \mathrm{~Hz}), \delta 2.83(\mathrm{H}-4, d d, \\
J=16.0,5.4 \mathrm{~Hz}), \delta 4.04(\mathrm{H}-3, m), 4.55(\mathrm{H}-2, d, \\
J=7.5 \mathrm{~Hz}), \delta 5.91(\mathrm{H}-6, d, J=2.2 \mathrm{~Hz}), \delta 6.75(\mathrm{H}-8, \\
d, J=8.0 \mathrm{~Hz})\end{array}$ \\
\hline & (-)-Epicatechin & $\begin{array}{c}\delta 2.72(\mathrm{H}-4, d d, J=16.8 .2 .8 \mathrm{~Hz}), \delta 2.85(\mathrm{H}-4, d d, \\
J=16.7,4.6 \mathrm{~Hz}), \delta 5.91(\mathrm{H}-6, d, J=10.0,2.3 \mathrm{~Hz}) \\
\delta 6.96(\mathrm{H}-8, d, J=2.2 \mathrm{~Hz})\end{array}$ \\
\hline & Quercetin & $\begin{array}{l}\delta 7.71\left(\mathrm{H}-2^{\prime}, d, J=2.0 \mathrm{~Hz}\right), \delta 7.66\left(\mathrm{H}-6^{\prime}, d d, J=8.6\right. \\
2.0 \mathrm{~Hz}), \delta 6.99\left(\mathrm{H}^{\prime}-5^{\prime}, d, J=8.6 \mathrm{~Hz}\right), \delta 6.49(\mathrm{H}-8 \\
d, J=1.8 \mathrm{~Hz}), \delta 6.28(\mathrm{H}-6, d, J=1.8 \mathrm{~Hz})\end{array}$ \\
\hline & $\begin{array}{l}\text { Quercetin 3-O } \\
\text { rhamnoside }\end{array}$ & $\begin{array}{c}\delta 7.32\left(\mathrm{H}-2^{\prime}, d, J=2.0 \mathrm{~Hz}\right), \delta 7.27\left(\mathrm{H}-6^{\prime}, d d, J=8.0\right. \\
2.0 \mathrm{~Hz}), \delta 6.89\left(\mathrm{H}^{\prime} 5^{\prime}, d, J=8.0 \mathrm{~Hz}\right), \delta 6.97(\mathrm{H}-8 \\
d, J=1.8 \mathrm{~Hz}), \delta 6.27(\mathrm{H}-6, d, J=1.8 \mathrm{~Hz})\end{array}$ \\
\hline & Gallic acid & $\delta 7.03(\mathrm{~s})$ \\
\hline & $p$-Benzoic acid & $\begin{array}{l}\delta 6.83(\mathrm{H}-3, \mathrm{H}-5, \mathrm{~d}, J=8.7 \mathrm{~Hz}), \delta 7.94(\mathrm{H}-2, \mathrm{H}-4, \mathrm{~d}, \\
\quad J=8.8 \mathrm{~Hz})\end{array}$ \\
\hline & Rutin & $\begin{array}{l}\delta 7.66\left(\mathrm{H}-2^{\prime}, d, J=2.0 \mathrm{~Hz}\right), \delta 7.62\left(\mathrm{H}-6^{\prime}, d d, J=8.6,\right. \\
2.0 \mathrm{~Hz}), \delta 6.87\left(\mathrm{H}^{\prime} 5^{\prime}, d, J=8.6 \mathrm{~Hz}\right), \delta 6.39(\mathrm{H}-8, \\
d, J=1.8 \mathrm{~Hz}), \delta 6.21(\mathrm{H}-6, d, J=1.8 \mathrm{~Hz}), \delta 5.02 \\
\left(\mathrm{H}-1^{\prime}, d, J=7.7 \mathrm{~Hz}\right), \delta 4.54\left(\mathrm{H}^{\prime} 1^{\prime}, d, J=1.5 \mathrm{~Hz}\right), \\
\delta 1.12(\mathrm{H}-6, d, J=6.22 \mathrm{~Hz}),\end{array}$ \\
\hline & $p$-Coumaric acid & $\begin{array}{l}\delta 6.38\left(\mathrm{H}-8^{\prime}, d, J=16.0 \mathrm{~Hz}\right), \delta 6.84(d, J=8.8), \delta 7.50 \\
\quad(d, J=8.8), \delta 7.59\left(\mathrm{H}-7^{\prime}, d, J=16.0\right)\end{array}$ \\
\hline & Caffeic acid & $\begin{array}{l}\delta 6.24\left(\mathrm{H}-8^{\prime}, d, J=16.0 \mathrm{~Hz}\right), \delta 6.87(d, J=8.8), \delta 7.02 \\
\quad(d d, J=8.8,2.0 \mathrm{~Hz}), \delta 7.12\left(\mathrm{H}^{\prime} 7^{\prime}, d, J=2.0\right), \delta 7.52 \\
\quad\left(\mathrm{H}-7^{\prime}, d, J=16.0\right)\end{array}$ \\
\hline & Ferulic acid & $\begin{array}{l}\delta 7.56\left(\mathrm{H}^{\prime} 7^{\prime}, d, J=15.9 \mathrm{~Hz}\right), \delta 7.19\left(\mathrm{H}-2^{\prime}, d,\right. \\
J=2.1 \mathrm{~Hz}), \delta 7.10\left(\mathrm{H}-6^{\prime}, d d, J=8.4,2.1 \mathrm{~Hz}\right), \delta 6.88 \\
\left(\mathrm{H}-5^{\prime}, d, J=8.4\right), \delta 7.15(d, J=2.8), \delta 6.33\left(\mathrm{H}^{\prime} 8^{\prime}, d,\right. \\
J=15.9),\end{array}$ \\
\hline & Chlorogenic acid & $\begin{array}{l}\delta 7.60\left(\mathrm{H}-7^{\prime}, d, J=15.9 \mathrm{~Hz}\right), \delta 7.15\left(\mathrm{H}-2^{\prime}, d,\right. \\
J=2.1 \mathrm{~Hz}), \delta 7.05\left(\mathrm{H}-6^{\prime}, d d, J=8.4,2.1 \mathrm{~Hz}\right), \delta 6.87 \\
(d, J=8.4), \delta 6.36\left(\mathrm{H}-8^{\prime}, d, J=15.9\right), d 5.33(\mathrm{H}-3 . \\
\mathrm{t} d, J=10.0,4.8), \delta 4.21(\mathrm{H}-5, \text { br. } q, J=3.1)\end{array}$ \\
\hline & Sinapic acid & $\begin{array}{l}\delta 7.48\left(\mathrm{H}-7^{\prime}, d, J=16.0 \mathrm{~Hz}\right), \delta 6.93(\mathrm{H}-2, \mathrm{H}-6, \mathrm{~s} \\
J=8.8), \delta 6.37(\mathrm{H}-8, d, J=16.0 \mathrm{~Hz})\end{array}$ \\
\hline Fatty acids & $\begin{array}{l}\text { Common fatty acid } \\
\alpha \text {-Linolenic acid }\end{array}$ & $\begin{array}{l}\delta 0.88(\mathrm{H}-\omega, t, J=7.5 \mathrm{~Hz}), \delta 1.30\left(\mathrm{CH}_{2}, \text { br. } s\right) \\
\delta 0.97(\mathrm{H}-\omega, t, J=7.5 \mathrm{~Hz})\end{array}$ \\
\hline \multirow[t]{3}{*}{ Other compounds } & Choline & $\delta 3.24(s)$ \\
\hline & Adenine & $\delta 8.2(\mathrm{H}-3, s), \delta 8.21(\mathrm{H}-1, s)$ \\
\hline & Inositol & $\begin{array}{l}\delta 4.00(\mathrm{H}-2, t, J=2.8 \mathrm{~Hz}), \delta 3.6 \mathrm{l}(\mathrm{H}-6, \mathrm{H}-6, t, \\
J=9.9 \mathrm{~Hz}), \delta 3.44(\mathrm{H}-1, \mathrm{H}-3, d d, J=9.9,2.9 \mathrm{~Hz}), \delta \\
3.24(\mathrm{H}-5, t, J=9.3 \mathrm{~Hz})\end{array}$ \\
\hline
\end{tabular}


Acknowledgments

This work was partly supported by National Institute of Horticultural and Herbal Science, Rural Development Administration of Korea (Project No: PJ008700).

\section{References}

1. Verpoorte R, Choi YH, Kim HK (2007) NMRbased metabolomics at work in phytochemistry. Phytochem Rev 6:3-14

2. Schripsema J (2010) Application of NMR in plant metabolomics: techniques, problems and prospects. Phytochem Anal 21:14-21

3. Verpoorte R, Choi YH, Mustafa NR, Kim HK (2008) Metabolomics: back to basics. Phytochem Rev 7:525-537

4. Ebbels TMD, Cavill R (2009) Bioinformatic methods in NMR-based metabolic profiling. Prog Nucl Magn Reson Spectrosc 55:361-374

5. Verpoorte R, Choi YH, Kim HK (2010) Metabolomics: will it stay? Phytochem Anal $21: 2-3$

6. Kim HK, Choi YH, Verpoorte R (2010) NMRbased metabolomic analysis of plants. Nat Protoc 5:536-549

7. Kim HK, Choi YH, Verpoorte R (2011) NMRbased plant metabolomics: where do we stand, where do we go? Trends Biotechnol 29:267-275

8. Van der Kooy F, Maltese F, Choi YH, Kim HK, Verpoorte R (2009) Quality control of herbal material and phytopharmaceuticals with MS and NMR based metabolic fingerprinting. Planta Med 75:763-775

9. Choi YH, Sertic S, Kim HK, Wilson EG, Michopoulosa F, Lefeber AWM, Erkelens C, Verpoorte R (2005) Classification of Ilex species based on metabolomic fingerprinting using nuclear magnetic resonance and multivariate data analysis. J Agric Food Chem 53: 1237-1245

10. Kim HK, Saifullah K, Wilson EG, Kricun SDP, Meissner A, Goraler S, Deelder AM, Choi YH, Verpoorte R (2010) Metabolic classification of South American Ilex species by NMR-based metabolomics. Phytochemistry 71:773-784

11. Hendrawati O, Yao Q, Choi YH, Kim HK, Linthorst HJM, Erkelens C, Lefeber AWM, Verpoorte R (2006) Metabolic differentiation of Arabidopsis treated with methyl jasmonate using nuclear magnetic resonance spectroscopy. Plant Sci 170:1118-1124

12. Jahangir M, Kim HK, Choi YH, Verpoorte R (2008) Metabolomic response of Brassica rapa submitted to pre-harvest bacterial contamination. Food Chem 107:362-368

13. Leiss KA, Choi YH, Abdel-Farid IB, Verpoorte R, Klinkhamer PGL (2009) NMR metabolomics of thrips (Frankliniella occidentalis) resistance in Senecio hybrids. J Chem Ecol 35: 219-229

14. Ali K, Maltese F, Figueiredo A, Rex M, Fortes AM, Zyprian E, Pais MS, Verpoorte R, Choi YH (2012) Alterations in grapevine leaf metabolism upon inoculation with Plasmopara viticola in different time-points. Plant Sci 191-192:100-107

15. Choi YH, Kim HK, Hazekamp A, Erkelens C, Lefeber AW, Verpoorte R (2004) Metabolomic differentiation of Cannabis sativa cultivars using ${ }^{1} \mathrm{H}$ NMR spectroscopy and principal component analysis. J Nat Prod 67:953-957

16. Kim HK, Choi YH, Erkelens C, Lefeber AWM, Verpoorte R (2005) Metabolic fingerprinting of Ephedra species using ${ }^{1} \mathrm{H}-\mathrm{NMR}$ spectroscopy and principal component analysis. Chem Pharm Bull 53:105-109

17. Frédérich $\mathrm{M}$ et al (2004) Metabolomic analysis of Strychnos nux-pomica, icaja and ignatii extracts by ${ }^{1} \mathrm{H}$ nuclear magnetic resonance spectrometry and multivariate analysis techniques. Phytochemistry 65:1993-2001

18. Yang SY, Kim HK, Lefeber AWM, Erkelens C, Angelova C, Choi YH, Verpoorte R (2006) Application of two dimensional nuclear magnetic resonance spectroscopy to quality control of ginseng commercial products. Planta Med 72:364-369

19. Kim HK, Verpoorte R (2010) Sample preparation for plant metabolomics. Phytochem Anal 21:4-13 